\title{
SISTEM INFORMASI PERHITUNGAN DAN PENCATATAN AKUNTANSI PENGUPAHAN KARYAWAN MENGGUNAKAN METODE $A C C R U A L$ BASIS BERBASIS WEB (STUDI KASUS : PT HERONA EXPRESS CABANG CIREBON)
}

\author{
Ananda Savira Tamara Putri ${ }^{1}$, Amroni ${ }^{2}$ \\ Universitas Catur Insan Cendekia \\ Jl. Kesambi 202, Kota Cirebon, Jawa Barat. Telp: (0231) 220250 \\ E-mail: anandasavira29@gmail.com¹, Amroni@cic.ac.id ${ }^{2}$
}

\begin{abstract}
Abstrak
Sistem Perhitungan dan pencatatan upah karyawan pada PT Herona Express masih menggunakan sistem manual dan belum memiliki program khusus untuk mencatat data upah karyawan, dalam hal ini terdapat beberapa kelemahan. Kelemahan tersebut antara lain lamanya pembuatan laporan Upah, belum adanya proses otomatisasi perhitungan komponen Upah, belum adanya perhitungan Pajak Penghasilan Pasal 21 dan masalah Upah bagi karyawan merupakan hal yang sensitif dan berpengaruh langsung pada produktivitas kerja individu. Dibuatnya Aplikasi Perhitungan dan pencatatan upah karyawan menggunakan Metode Accrual Basis ini bertujuan Mengetahui proses otomatisasi perhitungan komponen Upah karyawan pada bagian keuangan. Sistem Perhitungan dan pencatatan upah karyawan ini dikembangkan dengan menggunakan bahasa pemograman PHP MyAdmin, dengan menggunakan database managemen system MySQL, dan dapat berjalan pada sistem jaringan dimana perangkat lunak database di tempatkan di server database. Dengan dikembangkannya aplikasi Web menjadi jaringan dapat disimpulkan bahwa sistem ini dapat melakukan pengendalian akses akses informasi lebih mudah karena setiap klien atau user yang menggunakan aplikasi tersebut akan lebih mudah mengakses informasi yang diberikan oleh perusahaan karena aplikasi ini berbasis web sehingga bisa diakses secara online dengan menggunakan bermacam-macam perangkat dan aplikasi web yang cenderung bisa digunakan oleh hampir semua perangkat yang menyertakan browser, hal tersebut karena aplikasi berbasis web cenderung jauh lebih ringan dan lebih murah.
\end{abstract}

Kata Kunci : Sistem,Informasi, Pencatatan, Upah, Accrual Basis

\begin{abstract}
The calculation system and recording of wages of employees at PT Herona Express still use a manual system and do not have a special program to record employee wage data, in this case there are several weaknesses. These weaknesses include the length of the Wage report creation, the absence of an automation process for calculating Wage components, the absence of Article 21 Income Tax calculations and the Wage issue for employees is sensitive and has a direct effect on individual work productivity. Application Creation Calculation and recording of employee wages using the Accrual Basis Method aims to Know the process of automating the calculation of employee Wages components in the financial section. This system of calculation and wage recording is developed using the PHP MyAdmin programming language, using the MySQL database management system, and can run on network systems where database software is placed on the database server. With the development of Web applications into networks it can be concluded that this system can control access to information access more easily because each client or user who uses the application will be easier to access information provided by the company because this application is web-based so that it can be accessed online using various kinds of devices and web applications that tend to be used by almost all devices that include browsers, this is because web-based applications tend to be much lighter cheaper Keywords: Systems, Information, Recording, Wage, Accrual Basis.
\end{abstract}




\section{PENDAHULUAN}

Tujuan berdirinya perusahaan pada umumnya adalah untuk mendapatkan laba atas hasil usaha yang dijalankan. Berkembangnya perusahaan akan membutuhkan lebih banyak tenaga kerja untuk menunjang kegiatannya, namun terkadang ditemui kesulitan dalam pencarian tenaga kerja yang berkualitas karena harus mempertimbangkan kesejahteraan dan upah yang kompetitif dengan perusahaan lain. Upah adalah balas jasa dalam bentuk uang yang diterima tenaga kerja berdasarkan kesepakatan yang telah ditentukan sebelumnya. Prosedur pengupahan memerlukan informasi yang relevan, efektif dan efesien untuk dalam pengambilan keputusan serta dalam melaksanakan fungsi- fungsinya. Oleh karena itu, diperlukan suatu sistem informasi akuntansi yang mendukung kebutuhan manajemen dalam mengelola data keuangan perusahaan khususnya pengupahan. Sistem informasi akuntansi pengupahan merupakan faktor yang menentukan bagaimana kelangsungan kinerja karyawan dalam suatu perusahaan, oleh karena itu sistem informasi akuntansi pengupahan yang terdapat di dalam suatu perusahaan sangat berperan penting dalam pembayaran upah khususnya mengenai cara pembayaran upah, baik secara langsung kepada karyawan maupun melalui bank.

PT. Herona Express adalah perusahaan yang bergerak di bidang jasa ekspedisi atau pelayanan pengiriman via kereta api dan truk box. Wilayah distribusi layanannya lebih dari 50 kota di Pulau Jawa, Bali dan Madura. Perusahaan ini dirintis tahun 1966 dengan nama awal Hero Indonesia Agency, sebagai salah satu perusahaan sub kontraktor PT Kereta Api. PT. Herona Express cabang Cirebon terletak di Jalan Kramat V (dalam area Stasiun Kejaksan). Di kantor cabang ini, perusahaan PT. Herona Express memperkerjakan 40 orang karyawan. PT. Herona Express cabang Cirebon menjalankan operasi kerja hampir setiap hari, kecuali hari libur nasional. Beberapa aktivitas dari PT.Herona Express saat ini masih ada yang belum terkomputerisasi. Aplikasi komputerisasi hanya digunakan untuk pendataan dan pencatatan transaksi penerimaan kiriman. Kegiatan operasional lainnya hanya menggunakan aplikasi pengolah kata dan pengolah angka. Salah satu aplikasi komputer yang masih dalam menggunakan pengolah angka adalah sistem pengupahan. Penggunaan aplikasi pengolah angka/spreadsheet ini digunakan untuk membuat laporan pengupahan karyawan. Hal ini memiliki banyak kendala yaitu lamanya pembuatan laporan Upah, belum adanya proses otomatisasi perhitungan komponen Upah, belum adanya perhitungan Pajak Penghasilan Pasal 21 dan masalah Upah bagi karyawan merupakan hal yang sensitif dan berpengaruh langsung pada produktivitas kerja individu. Selain itu, untuk bagian admin dalam memproses rincian dana yang akan dikeluarkan untuk pembayaran upah kepada karyawan belum mempunyai aplikasi khusus, dan untuk proses pencatatan data keuangan belum menggunakan laporan keuangan sesuai dengan standar akuntansi keuangan yang efektif untuk menghasilkan laporan keuangan yang cepat dan akurat diperusahaan.

Sistem berbasis komputer dapat digunakan untuk menghasilkan laporan upah, otomatisasi upah, perhitungan komponen perhitungan upah serta mengurangi kesalahan dalam pencatatan pengupahan Dalam akuntansi pencatatan pengupahan itu merupakan kegiatan utama dalam suatu perusahaan. Dalam melakukan proses pengupahan diperlukan kerjasama yang baik antar bagian yang ada dalam perusahaan tersebut. Salah satu perhitungan pengupahan ialah menggunakan metode accrual basis. Accrual basis adalah suatu beban yang belum dibayar ataupun suatu pendapatan yang belum diterima. Perhitungan yang belum dicatat harus diakui terlebih dahulu sebelum laporan keuangan disusun. (Marianus sinaga,1992).

Oleh karena itu berdasarkan uraian yang telah dijelaskan maka penelitian ini akan difokuskan pada "Sistem Informasi Perhitungan Dan Pencatatan Akuntansi Pengupahan Karyawan Menggunakan Metode Accrual Basis Berbasis Web (Studi Kasus : PT Herona Express Cabang Cirebon)”.

\section{KAJIAN PUSTAKA}

\subsection{Sistem Informasi}

Sistem informasi dapat diartikan sebagai suatu kombinasi dari manusia,hardware,software, serta media yang berfungsi mengelola informasi agar informasi tersebut dapat tersaji dengan baik dan dapat memenuhi kebutuhan informasi bagi perusahaan sebagai dasar dalam mengambil keputusan. [1]

Sistem Informasi Perhitungan dan Pencatatan Akuntansi Pengupahan Karyawan Menggunakan Metode Accrual Basis Berbasis Web (Studi Kasus : PT. Herona Express Cabang Cirebon- 


\subsection{Pencatatan Akuntansi}

Gaji adalah suatu kompensasi yang dibayarkan oleh perusahaan kepada karyawan sebagai balas jasa atas kinerja yang telah diberikan terhadap perusahaan. Kompensasi tersebut biasanya diberikan bulanan kepada karyawan. Sedangkan upah umumnya merupakan pembayaran atas penyerahan jasa yang dilakukan oleh karyawan pelaksana (buruh). Upah dibayarkan berdasarkan hari kerja, jam kerja atau jumlah satuan produk yang dihasilkan. [2]

\subsection{Pajak Penghasilan Pasal 21}

PPh Pasal 21 adalah pajak atas penghasilan berupa Upah, upah, honorarium, tunjangan, dan pembayaran lain dengan nama dan dalam bentuk apapun sehubungan dengan pekerjaan atau jabatan, jasa, dan kegiatan yang dilakukan oleh orang pribadi subjek pajak dalam negeri, sebagaimana dimaksud dalam pasal 21 Undang-undang Pajak penghasilan. [3]

\subsection{Undang-undang Republik Indonesia Nomor 13 Tahun 2003 tentang Ketenagakerjaan}

(1) Setiap pengusaha wajib melaksanakan ketentuan waktu kerja.

(2) Waktu kerja sebagaimana dimaksud dalam ayat (1) meliputi : a. 7 (tujuh) jam 1 (satu) hari dan 40 (empat puluh) jam 1 (satu) minggu untuk 6 (enam) hari kerja dalam 1 (satu) minggu; atau b. 8 (delapan) jam 1 (satu) hari dan 40 (empat puluh) jam 1 (satu) minggu untuk 5 (lima) hari kerja dalam 1 (satu) minggu.

(3) Ketentuan waktu kerja sebagaimana dimaksud dalam ayat (2) tidak berlaku bagi sektor usaha atau peker-jaan tertentu.

(4) Ketentuan mengenai waktu kerja pada sektor usaha atau pekerjaan tertentu sebagaimana dimaksud dalam ayat (3) diatur dengan Keputusan Menteri. [4]

\subsection{Perbedaan Accrual Basis Dan Cash Basis}

Accrual Basis merupakan tekhnik pencatatan akuntansi dimana pencatatan dilakukan ketika terjadinya transaksi walaupun kas belum diterima atau dikeluarkan sedangkan Cash Basis merupakan tekhnik pencatatan akuntansi dimana pencatatan hanya dilakukan ketika kas diterima dan dikeluarkan. [5]

\subsection{Sistem Pengendalian Internal}

Sistem pengendalian intern meliputi struktur organisasi, metode dan ukuran-ukuran yang dikoordinasikan untuk menjaga kekayaan organisasi, mengecek ketelitian dan keandalan data akuntansi, mendorong efisiensi dan mendorong dipatuhinya kebijkan manajemen. [6]

\section{ANALISA DAN PERANCANGAN}

Analisa pada sistem yang berjalan dilakukan agar dapat memahami kendala-kendala pada perusahaan PT.Herona Express Kota Cirebon, terkait dengan penerapan sistem baru. Sistem baru yang diusulkan nantinya diharapkan akan mampu memenuhi kebutuhan dari PT.Herona Express Kota Cirebon.

\subsection{Flowchart Pengupahan Yang Berjalan}

Penjelasan prosedur dan naratif dan penggambaran dengan flowchart dilakukan untuk mempermudah mendeskripsikan alur sistem akuntansi biaya pencatatan upah karyawan yang sedang berjalan pada PT. Herona Express. 


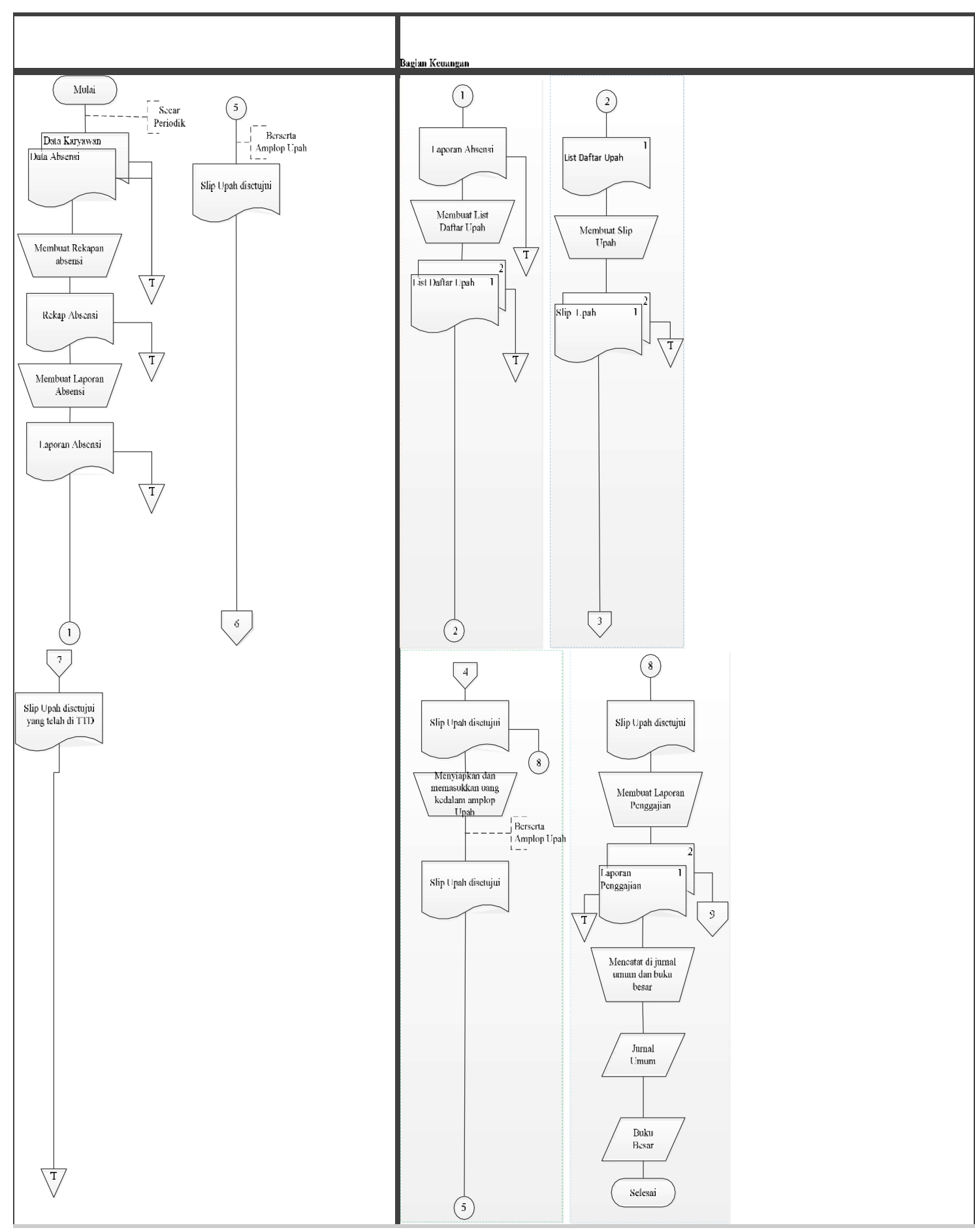

Gambar 1. Flowchart Prosedue Pengupahan Karyawan dengan Metode Accrual Basis pada PT. Herona Express 


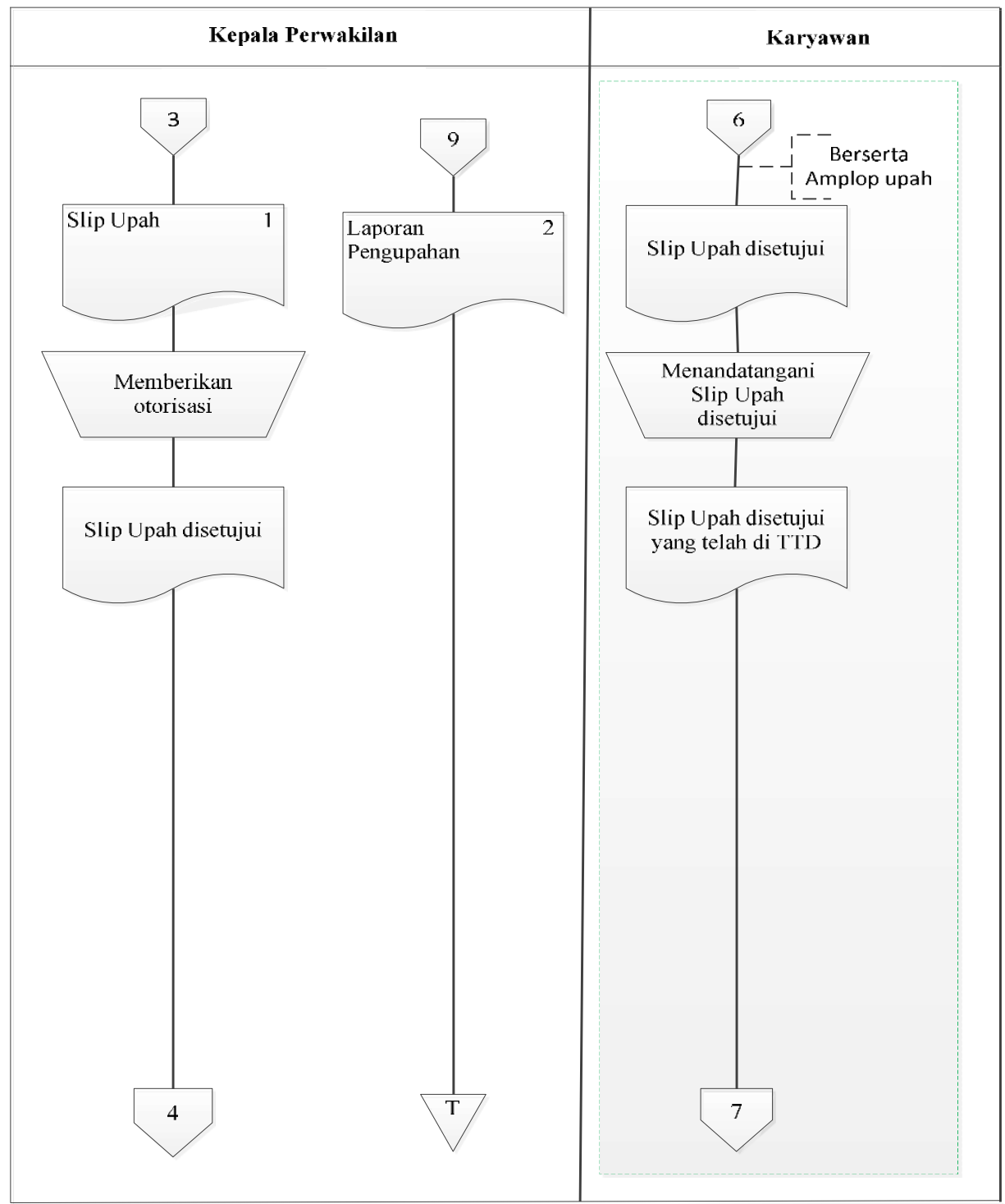

Gambar 2. Flowchart Prosedur Pengupahan Karyawan dengan Metode Accrual Basis padaPT. Herona Express (Lanjutan)

\subsection{Analisa dan perancangan sistem yang diusulkan perhitungan upah karyawan dengan Metode Accrual basis}

Flowmap komputerisasi dilbuat untuk mempermudah dalam mendeskripsikan alur sistem perhitungan upah karyawan yang akan diimplementasikan pada PT. Herona Express Gambar 3 adalah flowmap komputerisasi perhitungan upah karyawan. 


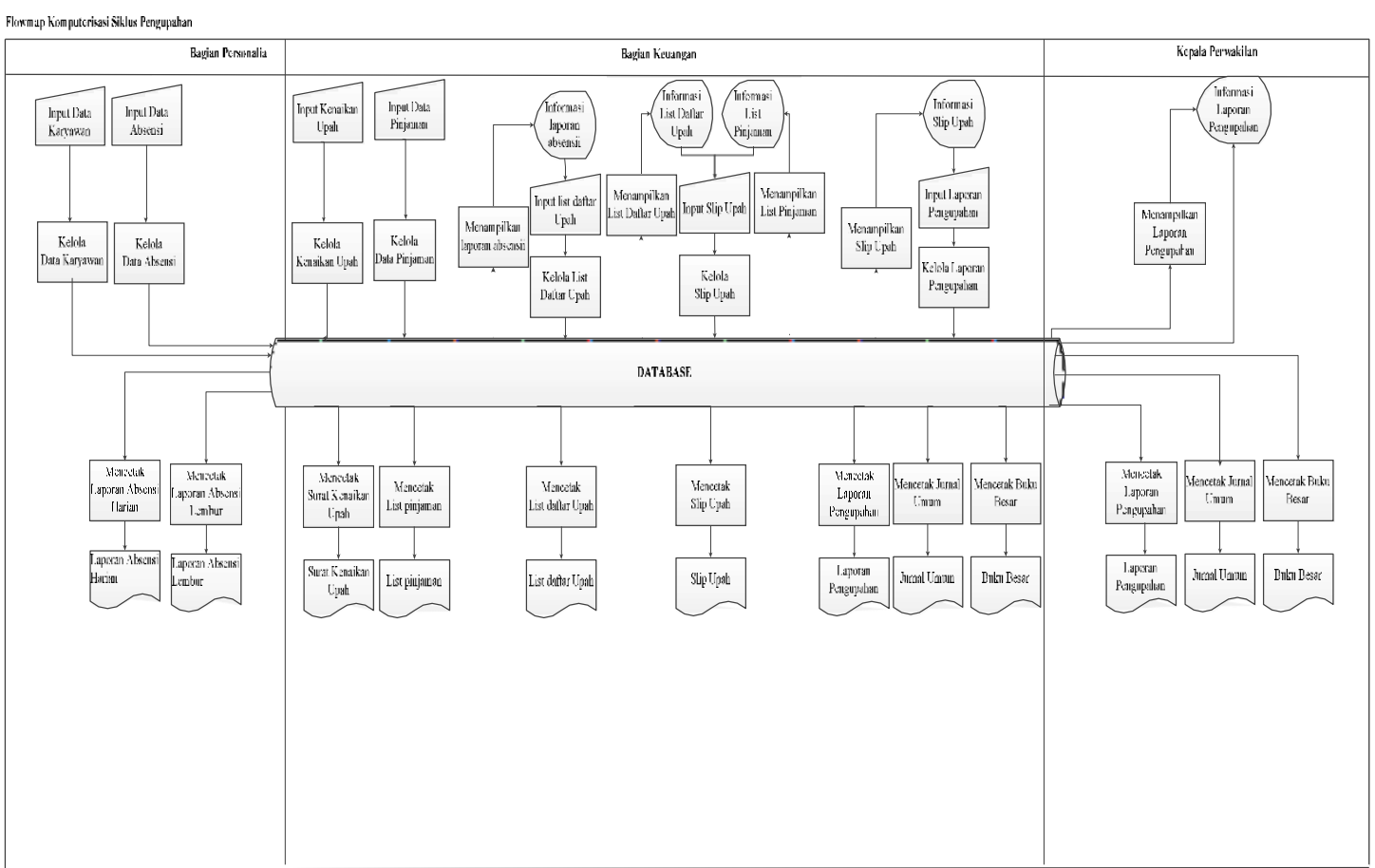

Gambar 3. Flowmap Komputerisasi Prosedur Pehitungan Upah Karyawan pada PT. Herona Express Kota Cirebon

\subsection{Entity Relationship Diagram (ERD)}

Entity relationship diagram memiliki fungsi memberikan gambaran hubungan antar entitas pada sebuahsistem. Adapun rancangan ERD dapat dilihat pada gambar 4:

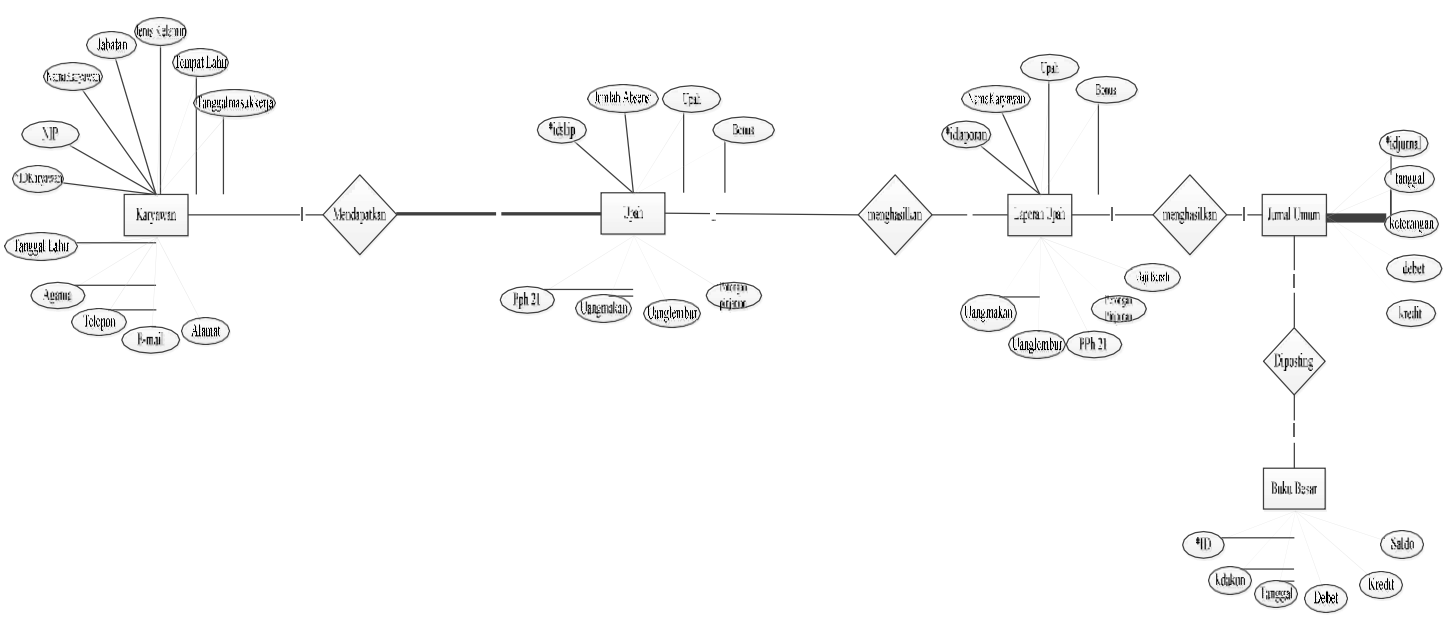

Gambar 4. Entity Relationhip Diagram

Sistem Informasi Perhitungan dan Pencatatan Akuntansi Pengupahan Karyawan Menggunakan Metode Accrual Basis Berbasis Web (Studi Kasus : PT. Herona Express Cabang Cirebon(Ananda Savira Tamara Putri, Amroni) 
4. HASIL DAN PEMBAHASAN

\subsection{Form Karyawan}

Form ini digunakan oleh Bagian Personalia untuk mencatat data karyawan yang ada pada herona express. form karyawan terlihat pada gambar 5. Form ini terdiri dari nik, nama karyawan, jenis kelamin, jabatan, tombol buat baru, tombol detail,tombol edit dan tombol hapus.

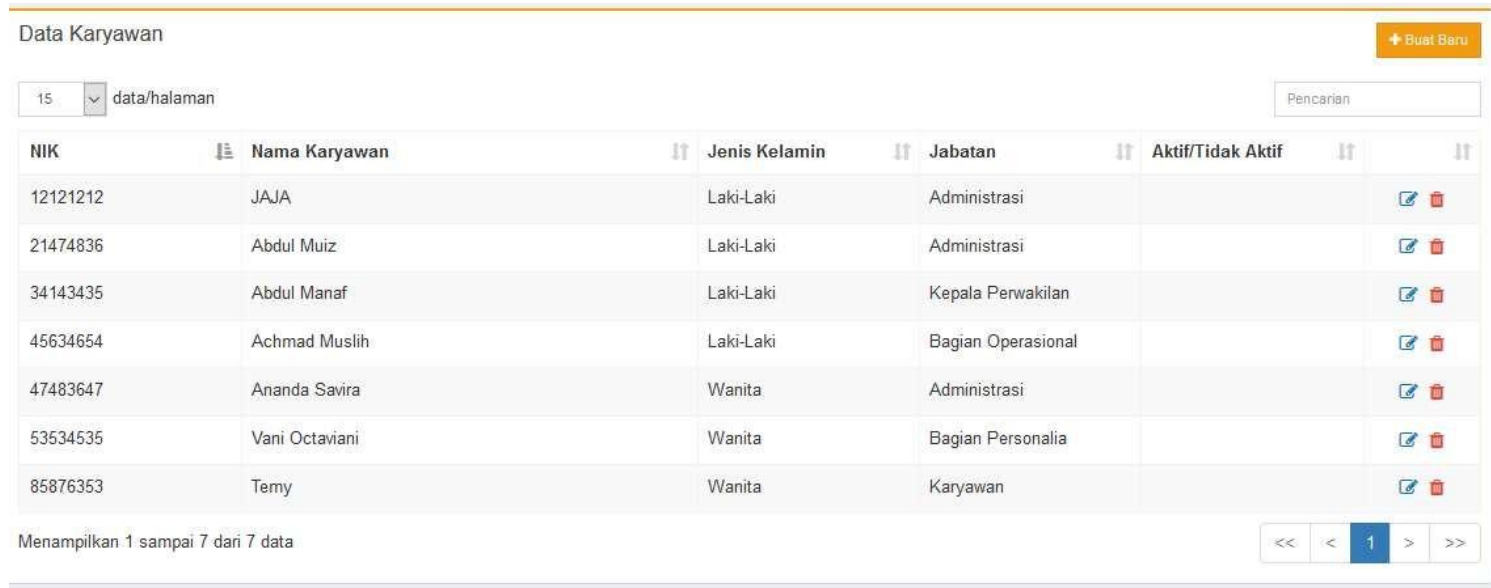

Gambar 5. Form Karyawan

\subsection{Form Absensi Karyawan}

Form ini digunakan oleh Bagian Personalia untuk menampilkan absensi karyawan di herona express, Form ini terdiri dari NIK, Nama Karyawan, tombol absensi karyawan baru, absensi detail, tombol cetak karyawan14.

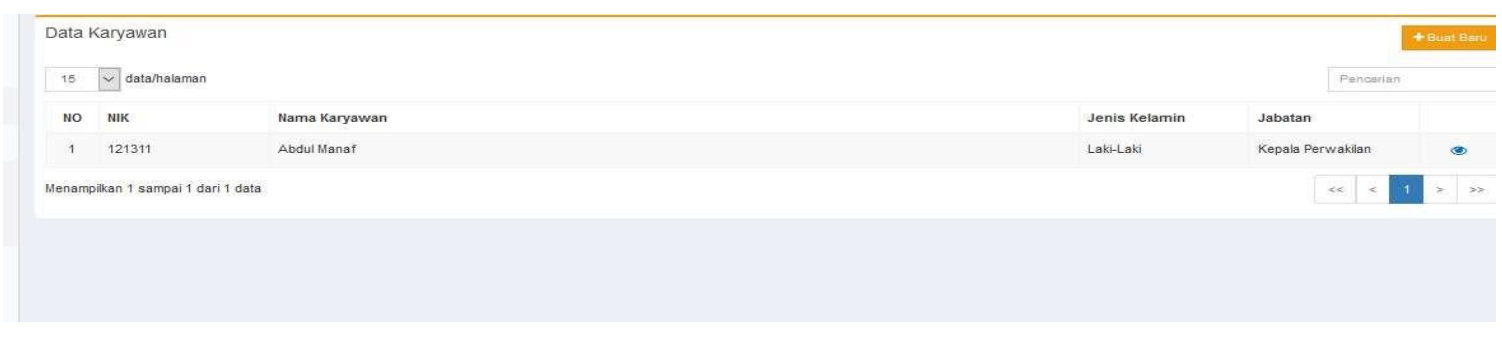

\section{Gambar 6. Absensi Karyawan}

\subsection{Data Laporan Absensi}

Laporan Absensi adalah hasil output akibat transaksi absensi untuk dapat mencetak laporan absensi atas persetujuan Bagian Personalia pada gambar 7.

PT Herona Express

J.Kramat V Kota Cirebon - 0231-234567

Rekapitulasi Absensi

\begin{tabular}{|c|c|c|c|c|c|c|c|}
\hline \multirow{2}{*}{ so } & \multirow{2}{*}{$\mathrm{x} D$} & \multirow{2}{*}{ SAMA LENGKAS } & \multicolumn{4}{|c|}{ TANGGAL } & \multirow{2}{*}{ JML HAOIR } \\
\hline & & & ${ }_{01}$ & 02 & a4 & 05 & \\
\hline 1 & 121311 & Asdul Manaf & II & III & II & iI & 0 \\
\hline
\end{tabular}

CIRFBON, DE FEBRLARI 2019

Gambar 7. Laporan Absensi 


\subsection{Form Upah}

Form ini digunakan oleh Bagian Keuangan untuk menampilkan upah karyawan terlihat pada gambar 8. Form ini berisi NIK, Nama Karyawan, Jabatan, dan Bulan. Pada form ini hanya terdapat tombol detail.

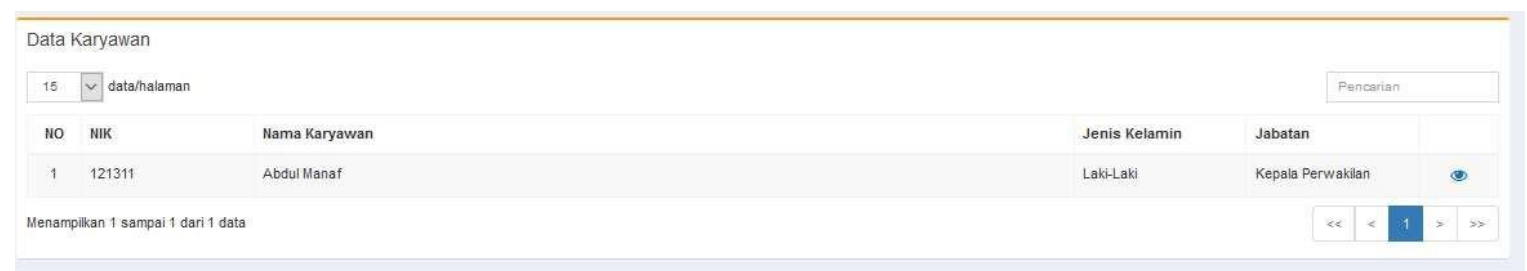

Gambar 8. Form Upah

\subsection{Slip Upah}

Slip Upah adalah hasil output dari form Slip Upah yang berisikan seluruh total upah dan pajak penghasilan pasal 21. Slip Upah dikeluarkan atas persetujuan Bagian Keuangan.

PT Herona Express

J.Kramat V Kota Cirebon - 0231-234567

SLIP UPAH

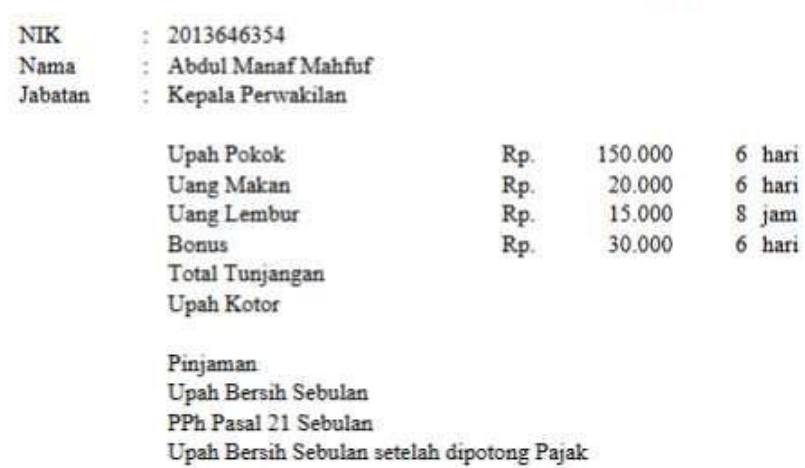

CIREBON, 09 MARET 2019

Vani Octaviani

Gambar 9. Slip Upah

\subsection{Laporan Upah}

Laporan Upah berisikan seluruh upah karyawan herona express. Laporan Upah Karyawan dikeluarkan oleh Bagian Keuangan kemudian dapat dilihat oleh Kepala Perwakilan pada gambar 18.

Sistem Informasi Perhitungan dan Pencatatan Akuntansi Pengupahan Karyawan Menggunakan Metode Accrual Basis Berbasis Web (Studi Kasus : PT. Herona Express Cabang Cirebon- 
PT Herona Express

Jl.Kramat V Kota Cirebon - 0231-234567

09 Maret 2019

LAPORAN UPAH

Periode
\begin{tabular}{|c|c|l|r|r|r|}
\hline NO & NIP & \multicolumn{2}{|c|}{01 Maret $2019 \quad$ NAMA KARYAWAN } & TANGGAL & TOTAL UPAH \\
\hline 1 & 2013646354 & Abdul Manaf Mahfuf & $02-03-2019$ & 1.220 .000 \\
\hline
\end{tabular}

CIREBON, 09 MARET 2019

Vani Octaviani

Gambar 10. Laporan Upah

\subsection{Posting Jurnal}

Form ini digunakan oleh Kepala Pewakilan untuk melakukan pemostingan jurnal baik jurnal untuk mencatat seluruh pengeluaran upah karyawan pada waktu tertentu. Form posting jurnal terlihat pada gambar 11.

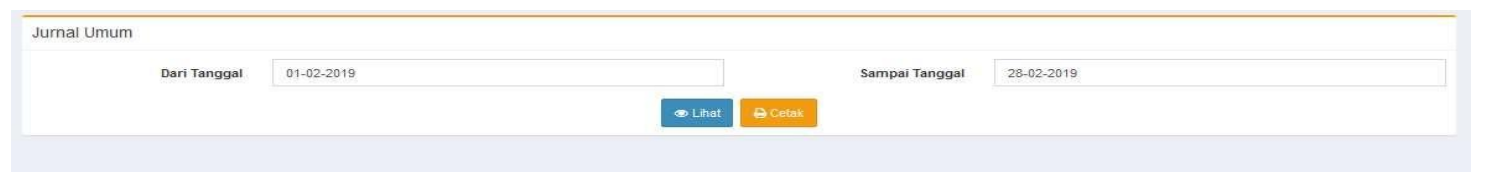

Gambar 11. Posting Jurnal

\subsection{Jurnal Umum}

Jurnal Umum berisikan catatan akuntansi dari laporan upah karyawan pada periode tertentu yang merupakan keluaran dari form cetak Jurnal Umum. Jurnal umum dikeluarkan oleh Bagian Keuangan kemudian dapat dilihat oleh Kepala Perwakilan pada gambar 12.

PT Herona Express

J.Kramat V Kota Cirebon - 0231-234567

99 Maret 2019

JURNAL UMTUM

\begin{tabular}{|c|c|c|c|}
\hline TANGGAL & KETERAVGAX & DEBET & KREDIT \\
\hline 02-03-2019 & Pinjamas Karyawan & 100.000 & 0 \\
\hline 02-03-2019 & Kas & 0 & 100.000 \\
\hline 08-03-2019 & Binya Upah & 1.420 .000 & 0 \\
\hline 08-03-2019 & Hutang Upah & 0 & 1320.000 \\
\hline 08.03-2019 & Pinjaman Karyawan & 0 & 100.000 \\
\hline 09.03 .2019 & Hutang Upah & 1.320 .000 & 0 \\
\hline 09-03-2019 & Kas & 0 & $1,320,000$ \\
\hline & TOTAL & 2.840 .000 & 2.840 .000 \\
\hline
\end{tabular}

CIRFBOX, 09 MARET 2019

Vani Octaviani

Gambar 12. Jurnal Umum 


\subsection{Posting Buku Besar}

Form ini digunakan oleh Kepala Pewakilan untuk melakukan pemostingan buku besar dari jurnal untuk mencatat seluruh pengeluaran upah karyawan pada waktu tertentu. Form posting Buku Besar terlihat pada gambar 13 .

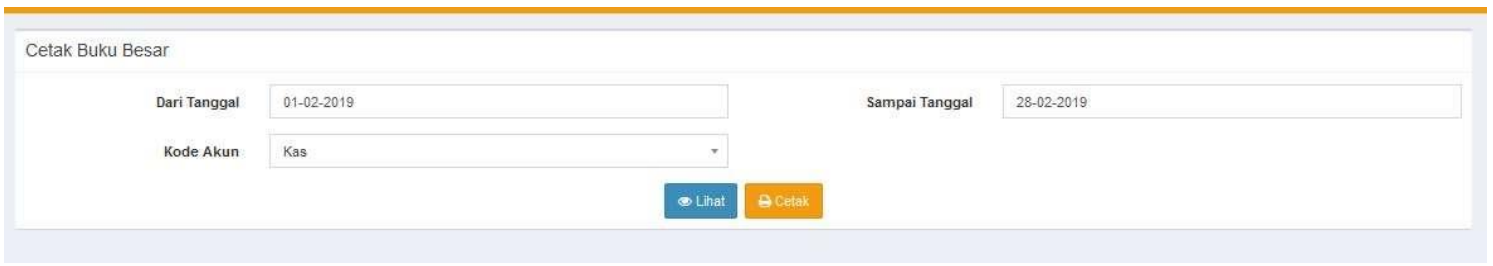

Gambar 13. Posting Buku Besar

\subsection{Buku Besar}

Buku Besar berisikan catatan akuntansi yang diposting dari jurnal umum yang merupakan keluaran dari form cetak Buku Besar. Buku besar dikeluarkan oleh Bagian Keuangan kemudian dapat dilihat oleh Kepala Perwakilan pada gambar 14.

PT Herona Express

J.Kramat V Kota Cirebon - 0231-234567

09 Maret 2019

BUKU BESAR

Periode $\quad 01$ Maret $2019 \quad-31$ Maret 2019
\begin{tabular}{|r|l|r|r|r|}
\hline TANGGAL & KETERANGAN & DEBET & 0 & 19 \\
\hline $02-03-2019$ & Kas & TOTAL & 0 & 1.320 .000 \\
\hline $09-03-2019$ & Kas & $\mathbf{0}$ & $\mathbf{1 . 4 2 0 . 0 0 0}$ \\
\hline
\end{tabular}

CIREBON, 09 MARET 2019

Vani Octaviani

Gambar 14. Buku Besar

\section{KESIMPULAN DAN SARAN}

\subsection{Kesimpulan}

Berdasarkan hasil observasi data dari PT. Herona Express serta pembahasan dari bab sebelumnya mengenai aplikasi sistem pengupahan karyawan, maka penyusun dapat memberikan kesimpulan yaitu :

1. Sistem komputerisasi dapat mempercepat pengolahan data dan pembuatan laporan upah.

2. Sistem komputerisasi dapat meningkatkan pelayanan pengupahan kepada semua karyawan yang bekerja pada PT. Herona Express.

3. Dengan adanya sistem komputerisasi dapat meminimalkan kesalahan yang dilakukan secara tulis tangan seperti pencatatan, perhitungan, pengecekan ataupun proses pemeriksaan yang membutuhkan ketelitian.

\subsection{Saran}

Berdasarkan hasil observasi, perancangan dan pembuatan aplikasi sistem pengupahan karyawan di PT. Herona Express Cirebon. Beberapa usulan untuk pengembangan sistem komputerisasi kedepan, antara lain :

1. Meningkatkan ketelitian dalam memasukkan data untuk mengurangi kesalahan sehingga dapat dihasilkan keluaran yang diinginkan.

Sistem Informasi Perhitungan dan Pencatatan Akuntansi Pengupahan Karyawan Menggunakan Metode Accrual Basis Berbasis Web (Studi Kasus : PT. Herona Express Cabang Cirebon- 
2. Melakukan backup secara berkala terhadap data-data penting untuk mengantisipasi hal-hal yang dapat merugikan perusahaan.

3. Diharapkan adanya pengembangan lebih lanjut dari sistem penggajian yang dirancang, sehingga menjadi sistem informasi yang terpadu untuk menanggulangi dan mengolah data yang lebih besar dimasa yang akan datang. Agar program aplikasi ini selalu berjalan dengan perkembangan data dan teknologi sebaiknya selalu mengadakan pembaharuan secara berkala terhadap program aplikasi yang ada atau melengkapi kelemahan-kelemahan program ini.

4. Diharapkan bagi peneliti selanjutnya untuk menyempurnakan program ini terutama pada fitur potongan pajak WP Badan dan SPT Tahunan bagi karyawan.

5. Perlunya pembatasan terhadap pihak yang berhak mengakses informasi pengupahan.

\section{DAFTAR PUSTAKA}

[1] Hery,Akuntansi Dasar 1 dan 2.Jakarta : PT Gramedia Widiasarana Indonesia,2014

[2] Jogiyanto, H. M. (2017). Analisis dan Desain (Sistem Informasi Pendekatan Terstruktur Teori dan Praktek Aplikasi Bisnis). Penerbit Andi.

[3] Kusrini M.kom,(2017), Strategi Perancangan dan Pengelolaan Basis Data, Andi, Yogyakarta,1-9, 1113.

[4] Mardiasmo.(2016).Perpajakan-Edisi Terbaru 2016. Penerbit Andi. Yogyakarta.

[5] Midjan, L., \& Susanto, A. (2001). Sistem Informasi Akuntansi: Pendekatan Manual Penyusunan Metode Dan Prosedur. Edisi Delapan, Bandung: Lingga Jaya.

[6] Mulyadi, Sistem Akuntansi Edisi 4, Jakarta: Salemba Empat, 2013

[7] Mulyadi, Sistem Akuntansi Edisi 4, Jakarta: Salemba Empat, 2016

[8] Sinaga, M. (1992). Prinsip-prinsip Akuntansi. 